\title{
Safety Impact of Enforcement, Penalty Level, and Fuel Prices
}

\author{
Prof. Hashem R. Al-Masaeid \\ Jordan University of Science and Technology Irbid, Jordan \\ almasaeid@yahoo.com
}

\begin{abstract}
In Jordan, traffic accidents form a major health issue. The problem of traffic accidents is ranked as the second leading cause of death. This study evaluated the safety effect of policy measures implemented in 2008. These measures included intensification of police enforcement, application of traffic law with stiff penalty levels, and the increase in fuel prices. To achieve this objective, traffic accidents data of 1998 through 2008 were obtained from Jordan traffic institute and other related sources.

In the evaluation, trend analysis was performed to explore possible safety impact of the applied safety policies and the sharp raise in fuel prices. Results of analyses indicated that the intensifications of police enforcement and applications of new traffic law with stiff penalty levels were found to have a significant positive safety effects on accidents and fatalities. The implementations of these policies were resulted in a reduction of $14 \%$ and $25 \%$ in traffic accidents and fatalities, respectively. On the other hand, investigation made in this study did not confirm the effect of fuel prices on traffic accidents or fatalities in Jordan.
\end{abstract}

Keywords: Traffic safety, policy measures, evaluation.

\section{INTRODUCTION}

In Jordan, the problem of traffic accidents is considered as a major health problem. The problem of traffic accidents started to appear as a serious problem since 1985. During the last 20 years, traffic accidents were increased from 15,884 in 1987 to 110,630 accidents in 2007. For the same period, the population and the number of vehicles were increased by about 2 and 3 times, respectively. Clearly, this situation is logical and expected, because Jordan has not yet adopted a comprehensive strategy to curb the scale and severity of this problem [1].

Considering traffic accidents as preventable and multidiscipline problem, many developed countries have implemented several policies and safety measures to overcome this problem [2]. These include traffic enforcement, education of roadway users, sound training programs for drivers, and highway engineering improvements. However, other safety studies indicated that the changing of drivers' behavior is an effective mean to improve safety. Such changes can be achieved through intensification of police enforcement level and application of traffic laws with high penalty level. For example, studies in France [3] and Finland [4] have concluded that intensifications of speed enforcement with large penalties are resulted in significant reduction of injuries and fatalities.

In Jordan, at the start of February 2008, as a result of the huge increase in traffic accident casualties and after a horrific bus accident on Irbid-Amman highway, his majesty King Abdullah II directed the governmental related authorities to formulate a comprehensive strategy to reduce traffic accidents and their consequences at the country level. Chairing a meeting of the higher council for traffic safety, the king said the strategy of traffic safety must be implemented in-line with a scheduled and clear action plans. Accordingly, the applied traffic law (No. 49, 2001) was replaced by a new temporary traffic law (No. 52, 2007). The new traffic law imposed stiffer penalties on drivers' violations. Also, traffic police activities were intensified and focused on certain driver's errors, particularly traffic speeding. Due to drivers complain, the restricted new law was relaxed by the start of June 2008, and the previous one (No. 49, 2001) was re-applied. However, a less restrictive permanent law (No. 49, 2008) was issued in July 2008 and applied since September 2008. On the other hand, police activities have been continued at the same level.

Concomitantly with the application of these safety measures, fuel prices were started to raise in Jordan. In fact, Jordan imports its fuel needs from Golf countries. In order to enhance the quality of life of the citizens, the government was partially subsidized the fuel prices. However, the government 
decided to change the mechanism of subsidization by the end of Jan. 2008. Consequently, fuel prices were liberated since the $8^{\text {th }}$ of Feb. 2008. As such, the prices were suddenly increased by $76 \%$ and $30 \%$ for diesel and gasoline, respectively. Due to the worldwide raise in fuel prices in 2008, further increase in prices were recorded in the subsequent months. By the end of July 2008, the cumulative increases in fuel prices were about $144 \%$ and $52 \%$ for diesel and gasoline, respectively. Compared with fuel consumption in 2007, the consumption of diesel in 2008 was decreased by 18\%; while the consumption of gasoline in 2008 was increased by $3.9 \%$ [5].

The major objectives of this study were: first; to quantify the safety impact of traffic law with stiffer penalty level and intensification of police enforcement. And, second; to explore the effect of fuel prices on traffic accidents. To achieve these objectives, traffic accidents data and other related information were obtained from the reports of Jordan traffic institute [6] and Ministry of Energy and Mineral Resources [5].

\section{EVAluATion ReSUlts}

\subsection{Overall Evaluation}

In the evaluation it was assumed that if the safety policies; including intensification of police enforcement and the application of traffic law with stiffer penalty levels, and the raise in fuel prices have not any impact on accidents and fatalities, then the past trend of accidents and fatalities will continue into the future. With this assumption, the past trend of traffic accidents and fatalities can be used to estimate the number of accidents and fatalities in 2008. Using accidents data for years 1998 through 2007 as presented in Table 1, Al-Masaeid [7] developed the following equations to estimate traffic accidents and fatalities in Jordan:

$\mathrm{ACC}=37.68 \mathrm{M}^{1.60}$

$\mathrm{F} / \mathrm{V}=22.5 \mathrm{M}^{-0.60}$

Where:

ACC $=$ expected number of traffic accidents, per year.

$\mathrm{M}=$ motorization level, number of registered vehicles per one-thousand of population.

$\mathrm{F}=$ expected traffic accident fatalities, per year.

$\mathrm{V}=$ number of registered vehicles in thousands.

Al-Masaeid [7] pointed out that Equations 1 and 2 and their parameters were found to be significant, with coefficient of determinations of 0.96 and 0.88 , respectively. Based on the previous assumptions, Equations 1 and 2 can be utilized to estimate traffic accidents and fatalities for 2008 , respectively. In 2008, there were 905,592 registered vehicles and a population of 5,850 thousands. Using Equation 1 with motorization level of 154.8 , the estimated number of accidents for 2008 is 117,500; while actual observed number of accidents was 101,066, as shown in Table 1. At 95\% significant level, a reduction of $14 \%$ in the total number of accidents might be concluded. On the other hand, traffic accidents of 2008 resulted in 740 fatalities compared with an estimated 995 fatalities, calculated using Equation 2. As such, a $25.6 \%$ reduction in the number of fatalities in 2008 was found to be significant at the $95 \%$ confidence level.

Table1. Traffic accidents and fatalities in 2007 and 2008

\begin{tabular}{|c|c|c|c|c|}
\hline Year & $\begin{array}{c}\text { Population } \\
\text { (thousand) }\end{array}$ & $\begin{array}{c}\text { Registered } \\
\text { Vehicles (thousand) }\end{array}$ & $\begin{array}{c}\text { No. of } \\
\text { Accidents (thousand) }\end{array}$ & Fatalities \\
\hline 1998 & 4755.8 & 389.20 & 43.343 & 612 \\
\hline 1999 & 4900.0 & 418.43 & 50.330 & 676 \\
\hline 2000 & 5039.0 & 473.34 & 52.796 & 686 \\
\hline 2001 & 5182.0 & 509.83 & 52.662 & 783 \\
\hline 2002 & 5329.0 & 542.81 & 52.913 & 758 \\
\hline 2003 & 5480.0 & 517.50 & 62.115 & 832 \\
\hline 2004 & 5350.0 & 612.33 & 70.266 & 790 \\
\hline 2005 & 5473.0 & 679.73 & 83.129 & 899 \\
\hline 2006 & 5600.0 & 755.48 & 89.055 & 992 \\
\hline 2007 & 5728.0 & 841.93 & 110.630 & 740 \\
\hline 2008 & 5850 & 905.59 & 101.066 & \\
\hline
\end{tabular}




\subsection{Effect of Fuel Prices}

In general, it is believed that the raise in fuel prices would affect drivers' behavior in two forms. First, drivers may reduce their non-essential tripes. This effect would reduce the level of travel and the traffic volumes on roads and the associated accident risk. Second, drivers may try to drive at lower speeds to reduce fuel consumption. Such reduction in driving speeds may lower levels of traffic accidents and the resulted fatalities.

As shown in Figure 1, fuel prices were started to raise in Feb. 2008. The highest cumulative increase was occurred in July, with nearly $120 \%$ and $55 \%$ for diesel and gasoline, respectively. Beyond July, the prices were reduced gradually. On the other hand, Figure 2 illustrates traffic accidents in 2008 and 2007. Comparison of figures 1 and 2 does not provide a solid background of the impact of fuel prices on traffic accidents. This result indicates that there is no clear association between fuel prices and traffic accidents. Although investigation of the impact of vehicle- kilometer of travel is more appropriate in this issue, field observations revealed that the raise in fuel prices did not have a sensible effect on traffic volumes on Jordanian roads. In fact, the reduction on traffic volumes was observed over few days in the mid of Feb. 2008; beyond which the effect was diminished. Furthermore, investigation of Table 2 indicates that the number of fatalities was continued to decrease even after the prices were started to drop beyond August 2008. Thus the reduction in number of fatalities in 2008 could not explained by fuel prices. Although these results are related to Jordanian drivers over a relatively short period of time, further investigation on the safety impact of fuel prices on accidents and their severities are recommended.

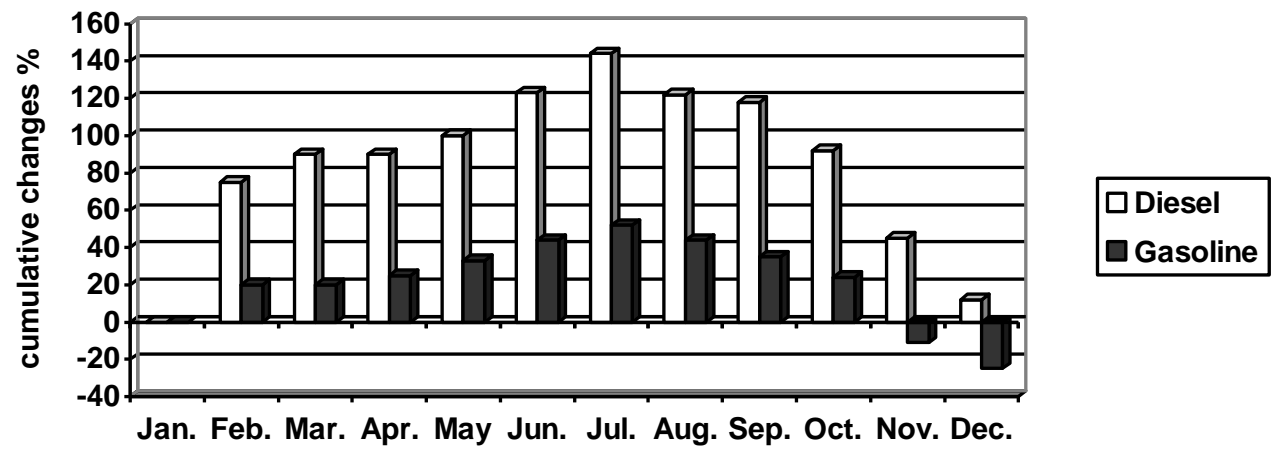

Fig1. Cumulative changes in fuel prices during 2008.

Table2. Traffic accidents and fatalities in 200 and 2008.

\begin{tabular}{|c|c|c|c|c|}
\hline \multirow{2}{*}{ Month } & \multicolumn{2}{|c|}{ No. of fatalities } & \multicolumn{2}{c|}{ No. of accident } \\
\cline { 2 - 5 } & 2007 & 2008 & 2007 & 2008 \\
\hline Jan. & 69 & 67 & 7788 & 8681 \\
\hline Feb. & 58 & 54 & 7759 & 6302 \\
\hline Mar. & 63 & 42 & 8691 & 6254 \\
\hline Apr. & 67 & 43 & 8506 & 6679 \\
\hline May & 71 & 49 & 9077 & 7679 \\
\hline Jun. & 97 & 64 & 9180 & 8565 \\
\hline Jul. & 73 & 71 & 10454 & 9755 \\
\hline Aug. & 102 & 72 & 10603 & 10233 \\
\hline Sep. & 91 & 60 & 10380 & 10551 \\
\hline Oct. & 124 & 61 & 10653 & 8687 \\
\hline Nov. & 101 & 87 & 9479 & 8554 \\
\hline Dec. & 76 & 740 & 8060 & 9126 \\
\hline Total. & 992 & & & 110630 \\
\hline
\end{tabular}

\subsection{Effect of Enforcement and Penalty Levels}

As mentioned before, two safety policies were implemented since the start of Feb. 2008. The first one was the application of the temporary law (No. 52, 2007); which imposed stiffer penalties on driver's violations, particularly excessive speeds. Due to drivers complain, this law was relaxed by the start of June, 2008 and replaced by less restrictive permanent law (No. 49, 2008). The second safety policy 
was the intensification of traffic enforcement; which have been continued up to the present time. Approximately, the number of police stations was increased by two folds. Consequently, the number of fines was increased to 2.14 millions in 2008, compared with 1.36 millions in 2007. The most important was the increase in number of fines for excessive speeding, which was increased from 144 thousands in 2007 to about 180 thousands in 2008. The overall positive effects of these policy measures were a decline in number of accidents and fatalities by $14 \%$ and $25.6 \%$, respectively.

Table 2 and Figure 2 show number of accidents by month for 2007 and 2008. Starting from Feb. 2008, Table 2 shows that both enforcement and changing of traffic law have a great reduction effect on both accidents and fatalities in 2008. Despite of the fact that the overall combined effects of the new traffic laws and increasing enforcement level had an overall positive influence in reducing accidents and fatalities, the application of law with stiffer penalty was the most effective. Compared with 2007 accidents, Figure 2 indicates that the most of accidents reduction in 2008 was occurred in February, March, April, and May. Approximately, 75\% of accidents reduction in 2008 occurred during these months. However, the temporary law with stiffer penalties was only applied during these months. Thus, implementation of an intensive enforcement accompanied with higher penalty levels may provide greater positive impact on traffic safety.

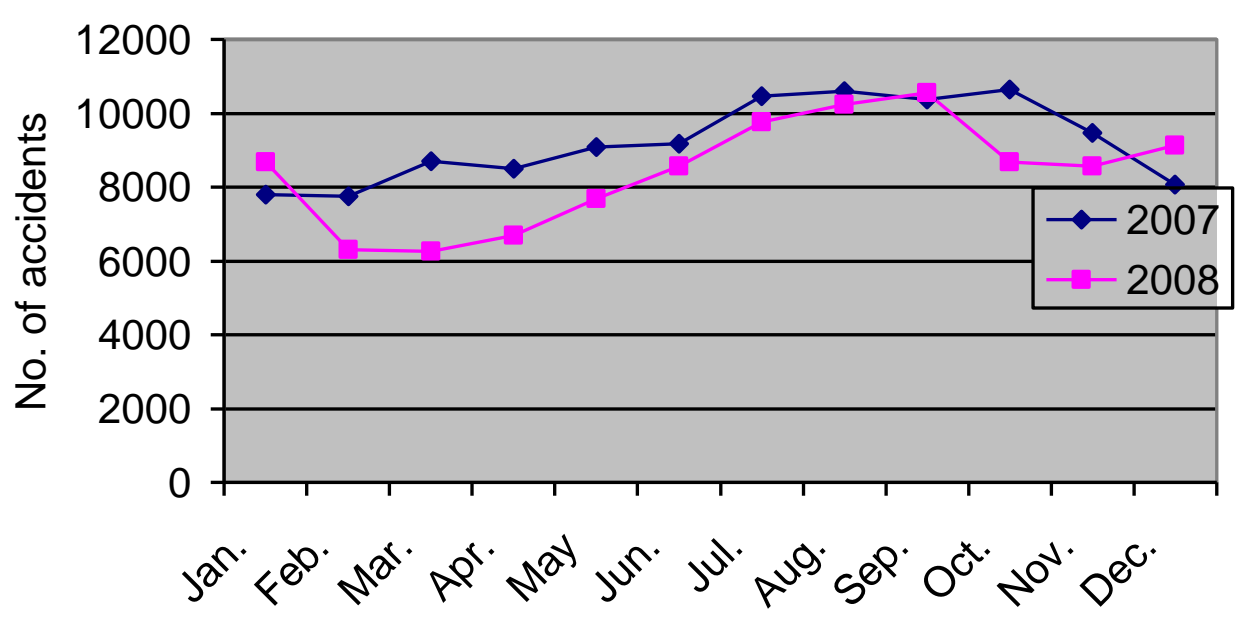

Fig2. Comparison of traffic accidents in 2007 and 2008.

It is worth mentioning that the old law (No. 49, 2001) was re-applied during the months of June to August 2008. Although the reduction in number of accidents during this period was marginal, the reduction in fatalities was continued. These reductions can be attributed to police enforcement; especially enforcement of traffic speeding. In reality, the safety effect of police enforcement is not unexpected in Jordan because most of traffic accidents are caused by driver's errors and their aggressiveness $[7,8]$.

Therefore, safety policy measures implemented in 2008; which included intensification of police enforcement and the application of stiffer traffic laws, were found to be effective in reducing the total number of traffic accidents and fatalities by $14 \%$ and $25.6 \%$, respectively. This result is consistent with findings of previous studies; which indicated that changing of attitudes of traffic law towards safety is an effective mean to improve drivers' behavior [9]. Such changes can be obtained through education and enforcement of traffic laws. In France, a dramatic increase in law enforcement over the 2001-2004 period reduced traffic fatalities by 32\% [3]. Similarly, intensification of speed control in Finland reduced the number of fatal accidents by about 13\% [4]. For a given enforcement level; however, results of this study indicated that a traffic law with stiffer penalty level would be more effective in reducing traffic accidents and their consequences.

\section{Conclusions}

Based on the analyses made in this study, the following results were concluded:

1. Safety polices measures; including intensification of police enforcement and changing of traffic law towards safety, undertaken in 2008, were found to be effective in reducing the number of traffic accidents and fatalities by $14 \%$ and $25.6 \%$, respectively. 
2. For the same enforcement level, application of traffic law with stiffer penalty level would significantly increase the safety effect.

3. For Jordan conditions, the raise in fuel prices during 2008 did not significantly affect traffic accidents or fatalities.

\section{REFERENCES}

[1] N. Katamine, "Persistent and continual worsening of the traffic accident situation in Jordan, Institute of Transportation Engineers Journal, ITE, Vol. 69, No. 3, 1999, pp. 28-34.

[2] H. Jorgensen, "The geography of traffic accident risk - some policy consequences, GeoHealth 2002, Victoria, University of Wellington, Dec. 3-5, 2002.

[3] A. Constant, L.R. Salmi, S. Lafont, M. Chiron, and Emmanuel, " The recent dramatic decline in road mortality in France: how drivers' attitudes towards road traffic safety changed between 2001 and 2004 in GAZEL cohort. Health Education Research, Vol. 23, No. 5, 2008, pp. 848858.

[4] R. Rijkka, and M. Mikko, "Effect of intensified automatic speed control and decreased tolerance on traffic safety, Nordic Road and transport Research Journal, No. 1, 2008, pp. 41.

[5] Ministry of Energy and Mineral Resources, The Yearly Report 2008, Amman, Jordan, 2008.

[6] Jordan Traffic Institute, Traffic accidents in Jordan 1997-2008, Ministry of Interior, Public Security Directorate, Amman, Jordan.

[7] H.R. Al-Masaeid, "Traffic accidents in Jordan, Jordan Journal of Civil Engineering, Vol. 3, No. 4, 2009, pp.331-343.

[8] M. Suliman, and W.H. Awad, "Aggressive driving is a major cause of traffic accidents and road rage in Jordan, Proc. Of the second international symposium on human factors in driver assessment, training and vehicle design, Park City, Utah, 22-24 July, 2003, pp. 182-187.

[9] P. Pelsmacker, and W. Janssens, "The effects of norms, attitudes and habits on speeding behavior: Scale development and model building and estimation, Accident Analysis and Prevention, Vol. 39, 2007, pp. 6-15.

\section{AUTHORS' BIOGRAPHY}

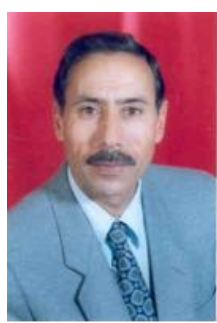

Hashem R. Al-Masaeid is professor of Civil Engineering at Jordan University of Science and Technology, Irbid, Jordan. He has a PhD in transportation from Purdue University, USA. Al-Masaeid is the former Minister of Transport of Jordan (2012), former Director General of Public Transport Regulatory Commission of Jordan (2006-2008), and former Vice President of Al al-Bayt University, Mafraq, Jordan (2008-2012). His areas of research include traffic engineering, highway geometric design, and public transport engineering. 